\title{
OPTIMASI AGROINDUSTRI STROBERI \\ OPTIMIZATION AGROINDUSTRI STRAWBERRIES
}

\author{
Oleh: \\ BETTY ROFATIN \\ DOSEN PRODI AGRIBISNIS FAKULTAS PERTANIAN \\ UNIVERSITAS SILIWANGI \\ email : bettyrofatin@yahoo.com \\ HENDAR NURYAMAN \\ DOSEN PRODI AGRIBISNIS FAKULTAS PERTANIAN \\ UNIVERSITAS SILIWANGI \\ email : hendarnuryaman@unsil.ac.id \\ SUYUDI \\ DOSEN PRODI AGRIBISNIS FAKULTAS PERTANIAN \\ UNIVERSITAS SILIWANGI \\ email : suyudi@unsil.ac.id
}

\begin{abstract}
Abstrak
Penggunaan sumberdaya yang optimal merupakan salah satu faktor penting yang akan menentukan keberhasilan produksi. Maka dari itu, kombinasi yang tepat dalam penggunaan sumberdaya yang tersedia dalam proses produksi harus dilakukan secara optimal. Tujuan penelitian ini untuk mengetahui kondisi aktual dan optimal agroindustri berbahan baku stroberi serta selisih penerimaan sebelum dan sesudah dilakukan optimasi. Metode yang digunakan adalah studi kasus dan penentuan lokasi secara purposive. Analisis menggunakan Linear Programming. Hasil penelitian menunjukkan Kondisi aktual berdasarkan penggunaan bahan baku adalah $40 \mathrm{~kg}$ untuk dodol stroberi, $20 \mathrm{~kg}$ untuk selai stroberi dan $20 \mathrm{~kg}$ untuk sirup stroberi. Berdasarkan penggunaan tenaga kerja adalah 24 JKO untuk dodol stroberi, 4 JKO untuk selai stroberi dan 4 JKO untuk sirup stroberi, sehingga dengan $30 \mathrm{~kg}$ dodol stroberi, $12 \mathrm{~kg}$ selai dan 17,5 kg ( $\approx 5$ botol) sirup stroberi, diperoleh penerimaan sebesar Rp. 2.505.000. Kondisi optimal berdasarkan penggunaan bahan baku adalah 39,67 kg untuk dodol stroberi, 40,33 $\mathrm{kg}$ untuk sirup stroberi, dan tidak memproduksi selai stroberi. Berdasarkan penggunaan tenaga kerja adalah $23,86 \mathrm{JKO}$ untuk dodol stroberi, 8,14 JKO untuk sirup stroberi, sehingga dengan $29,83 \mathrm{~kg}$ dodol stroberi dan $35,37 \mathrm{~kg}$ ( $\approx 71$ botol) sirup stroberi diperoleh penerimaan Rp. 2.552.716. Perbedaan penerimaan sebelum dan sesudah dilakukan optimasi adalah Rp. 47.716.
\end{abstract}

Kata kunci : Stroberi, Optimasi, Agroindusty, Linier programming

\section{PENDAHULUAN}

Indonesia adalah negara yang kaya akan jenis buah-buahan, ditambah dengan introduksi buah-buahan subtropik dari luar negeri yang ternyata dapat tumbuh dan berproduksi dengan baik dalam kondisi iklim seperti di Indonesia khususnya dataran tinggi. Salah satu buah subtropik yang telah lama dibudidayakan di Indonesia adalah stroberi. Buah stroberi secara ekonomi merupakan salah satu komoditas yang memiliki nilai tinggi dan pangsa pasar yang baik. Buah stroberi memiliki rasa yang khas, yaitu manis asam dan menyegarkan yang sangat disukai oleh konsumen. buah stroberi memiliki keterbatasan umur simpan dan mudah rusak (perishable). Stroberi dapat bertahan satu sampai 2 hari pada suhu ruang dan 4 hari di lemari es dengan suhu $0-1^{\circ} \mathrm{C}$ (Mitcham et al, 2000).

Pengolahan buah stroberi yaitu mengolah buah stroberi segar menjadi bahan makanan dalam bentuk lain. Pengolahan stroberi dilakukan untuk memperpanjang umur simpan, menampung kelebihan produksi pada 


\section{AIMBAR AGRIBISNIS \\ ISSN 2460-4321 \\ Volume 1 • Nomor 3 - Juli 2016}

saat panen raya atau memanfaatkan buah yang tidak memenuhi standar mutu buah segar karena ukurannya terlalu kecil atau bentuknya abnormal (Qanytah et all, 2011). Buah stroberi dapat diolah menjadi berbagai produk olahan seperti dodol, selai, sirup dan lain-lain. Agroindustri stroberi Kharisma merupakan salah satu agroindustri yang memproduksi berbagai variasi produk olahan stroberi di Desa Alamendah Kecamatan Rancabali Kabupaten Bandung. Ada beberapa jenis produk olahan stroberi yang diproduksi oleh agroindustri tersebut antara lain dodol, selai dan sirup stroberi. Saat ini, produk tersebut sudah menjadi ciri khas buah tangan daerah agrowisata Rancabali-Ciwidey. Selain itu rasa dodol, selai dan sirup stroberi yang khas dan enak menjadikannya tetap diminati sehingga permintaan terhadap produk tersebut kian meningkat. Tentu saja kondisi ini memberikan peluang pengembangan bisnis agroindustri olahan stroberi.

Dalam pengembangan agroindustri, modal merupakan elemen penting. Namun modal yang dibutuhkan dalam kegiatan agroindustri seringkali dihadapkan pada keterbatasan ketersediaannya. Modal yang terbatas itu terbagi menjadi dua yaitu modal kerja dan modal investasi, namun modal investasi tidak dijadikan kendala karena usaha ini sudah lama berjalan, sehingga kendala hanya berpusat pada modal kerja saja yang terdiri dari biaya utama dan yang menjadi biaya utama itu adalah bahan baku dan tenaga kerja. Untuk menghasilkan output yang maksimal perusahaan pasti akan dihadapkan pada bahan baku yang dimilikinya, tetapi untuk menghasilkan output yang maksimal, jumlah yang dibutuhkan akan melebihi yang disediakan. Kondisi ini mengharuskan perusahaan untuk melakukan kombinasi yang tepat agar kebutuhan tidak melebihi dari jumlah yang disediakan. Begitu juga dengan tenaga kerja yang merupakan bagian penting dalam proses produksi. Tenaga kerja dalam perusahaan harus mampu menghasilkan output secara maksimal. Tenaga kerja yang dibutuhkan untuk mengubah bahan baku menjadi output mungkin akan melebihi jumlah tenaga kerja yang tersedia.
J. Supranto (1983) menyatakan teknik pengambilan keputusan ialah perumusan berbagai alternatif tindakan sesuai dengan pemilihan alternatif yang tepat setelah suatu evaluasi (penilaian) mengenai efektifitasnya dalam mencapai tujuan yang dikehendaki pengambil keputusan. Pada umumnya setiap keputusan yang dibuat pasti ada tujuan yang akan dicapai. Intinya dalam keadaan sumberdaya yang terbatas harus dicapai suatu hasil yang optimal. Dengan kata lain bagaimana caranya agar dengan masukan (input) yang serba terbatas dapat dicapai hasil kerja yaitu keluaran (output) berupa produksi barang atau jasa yang optimal.

Tarmizi (2005), menyatakan bahwa secara matematis optimasi adalah cara mendapatkan keuntungan secara maksimal atau biaya yang minimal dari suatu fungsi tertentu dengan memperhatikan faktor-faktor pembatasnya. Jika persoalan yang akan diselesaikan dicari nilai maksimumnya, maka keputusannya berupa maksimasi. Optimasi dalam penyelesaian masalah merupakan suatu cara pengambilan keputusan sehingga didapatkan hasil penyelesaian yang optimal sesuai dengan kendala "state of nature" yang harus dipenuhi. Studi Deswani (2013) dengan menggunakan Linier Programming menunjukkan Pemakaian bumbu dan rempah serta santan kelapa sudah optimum pada agroindustri pengolahan rendang. Hal lain diungkapkan oleh Melli (2012) bahwa penggunaan bahan baku (lahan) pada usahatani kedelai dan padi belum optimal dan terjadi kelebihan dalam pencurahan tenaga kerja. Proses optimasi juga mampu meningkatkan pendapatan petani sebesar 54,6\% dari kondisi sebelumnya. Lebih lanjut Nasikh (2009) menyatakan bahwa untuk mendapatkan keuntungan yang maksimum Industri mebel kayu jati di jawa timur harus memproduksi 15 meja-kursi, 14 almari 1 pintu , 15 buffet 1 meter, 16 meja rias, 12 almari 2 pintu, 11 buffet 2 meter, 10 almari 3 pintu dan 9 tempat tidur.

Dari uraian diatas dapat diketahui bahwa, pengolahan buah stroberi menjadi dodol, selai dan sirup stroberi akan dihadapkan pada aktifitas penggunaan modal. Modal yang dikorbankan harus mampu menghasilkan 


\section{Optimasi Agroindustri Stroberi \\ Optimization Agroindustri Strawberries \\ BETTY ROFATIN, HENDAR NURYAMAN DAN SUYUDI}

kepentingan perusahaan baik itu kepentingan produksi maupun orientasi pada penerimaan maksimal. Melalui optimasi, perusahaan akan mampu mengkombinasikan faktor-faktor produksi agar penerimaan maksimal tetap diperoleh. Berdasarkan uraian tersebut, pertanyaan penelitian yang diajukan adalah Bagaimana mengoptimalkan penggunaan sumberdaya yang ada untuk memperoleh pendapatan yang optimal pada agroindustri yang berbahan baku stroberi. Maka tujuan dari penelitian ini adalah : (1) Menganalisis kondisi aktual agroindustri berbahan baku stroberi, (2) Menganalisis kondisi optimal agroindustri berbahan baku stroberi, dan (3) Menganalisis selisih penerimaan sebelum dan setelah dilakukan optimasi. Adapun lingkup optimasi yang dibahas adalah produk olahan stroberi yang diproduksi oleh agroindustri antara lain dodol, selai dan sirup stroberi.

\section{METODE PENELITIAN \\ Jenis dan Sumber Data}

Metode penelitian yang digunakan dalam penelitian ini adalah metode studi kasus pada Agroindustri Stroberi Kharisma di Desa Alam Endah, Kecamatan Rancabali, Kabupaten Bandung. Penentuan lokasi penelitian dipilih secara sengaja (purposive sampling) dengan pertimbangan bahwa agroindustri tersebut merupakan agroindustri yang paling banyak memproduksi olahan stroberi dengan berbagai variasi produk. Penelitian dilaksanakan pada bulan Juni - September 2015. Pengumpulan data pada penelitian ini terdiri dari data primer dan data sekunder. Pengolahan data dilakukan dengan bantuan paket program $Q M$ for windows.

\section{Metode Analisis Data}

Alat analisis data yang digunakan untuk menentukan Optimasi ini adalah dengan Linear Programming. LP ini adalah salah satu teknis analisis dari kelompok teknik riset operasional yang menggunakan model matematik. Tujuannya adalah untuk mencari, memilih dan menentukan alternatif yang terbaik dari sekian alternatif grafis dan metode analisis secara aljabar (metode simpleks). Soekartawi (1992), menyatakan bahwa setiap penyelesaian cara
Linear Programming untuk maksud mendesain perencanan yang baik agar memaksimumkan tujuan dapat diperoleh salah satunya dengan program memaksimumkan total penerimaan.

J. Supranto (1983) menambahkan untuk menentukan fungsi tujuan, harus ditentukan nilai variabel $\mathrm{x}$ melalui persamaan fungsi kendala. Kendala yang berpengaruh terhadap fungsi tujuan dibedakan menjadi dua yaitu ketersediaan bahan baku dan jumlah tenaga kerja.

Kendala bahan baku yaitu banyaknya bahan baku (a1n) yang dibutuhkan untuk pembuatan Dodol, selai dan sirup stroberi, formulasinya ditulis sebagai berikut :

$(a 11 . X 1)+(a 22 . X 2)+(a 32 . X 3) \leq b 1$

Kendala tenaga kerja, yaitu banyaknya tenaga kerja (a2n) yang dibutuhkan untuk mengerjakan kegiatan memproduksi dodol, selai dan manisan stroberi. Rumus matematikanya adalah :

$$
(a 21 . X 1)+(a 22 . X 2)+(a 32 . X 3) \leq b 2
$$

Sri Mulyono (2007) menyatakan, tujuan dari kombinasi produk adalah untuk memaksimumkan total penerimaan. Total penerimaan adalah jumlah penerimaan yang diperoleh dari masing-masing produk. Penerimaan dari produk satu adalah perkalian antara jumlah produk dengan harga per unit, penerimaan dua dan tiga ditentukan dengan cara serupa. Maka dapat dicari nilai dari total penerimaan pada fungsi tujuan yang dapat diformulasikan sebagai berikut :

$\mathrm{Z}=\mathrm{P} 1 \mathrm{X} 1+\mathrm{P} 2 \mathrm{X} 2+\mathrm{P} 3 \mathrm{X} 3$

Keterangan :

$\begin{array}{ll}\text { Z } & \text { : Total Penerimaan } \\ \text { P1 } & \text { : Harga jual dodol stroberi } \\ \text { X1 } & \text { : Jumlah hasil produksi dodol } \\ & \text { stroberi } \\ \text { P2 } & \text { : Harga jual selai stroberi } \\ \text { X2 } & \text { : Jumlah hasil produksi selai } \\ & \text { stroberi } \\ \text { P3 } & \text { : Harga jual sirup stroberi }\end{array}$




\section{A MiMBar AGRIBISNIS \\ ISSN 2460-4321 \\ Volume 1 - Nomor 3 - Juli 2016}

X3 : Jumlah hasil produksi sirup stroberi
Dari persamaan diatas, menghasilkan bentuk matrik dasar Linear Programming. Dapat dilihat pada Tabel 1.

Tabel 1. Matrik Dasar Linear Programming

\begin{tabular}{lccccc}
\hline \multicolumn{1}{c}{ Aktifitas atau Kegiatan } & \multicolumn{2}{c}{$\begin{array}{c}\text { Penggunaan Faktor Produksi per } \\
\text { Unit Kegiatan }\end{array}$} & \multicolumn{2}{c}{$\begin{array}{c}\text { RHS Faktor Produksi } \\
\text { yang Tersedia }\end{array}$} \\
\hline Tingkat Kegiatan & $\mathrm{X}_{1}$ & $\mathrm{X}_{2}$ & $\mathrm{X}_{3}$ & $\mathrm{~N}$ & Rata-rata \\
Fungsi Tujuan $(\mathrm{Z})$ & $\mathrm{C}_{1}$ & $\mathrm{C}_{2}$ & $\mathrm{C}_{3}$ & $\rightarrow$ & $\mathrm{Z}_{\text {maks }}$
\end{tabular}

Fungsi Batasan/Kendala :

Kebutuhan Faktor Produksi

\begin{tabular}{llllll}
1 & $\mathrm{a}_{11}$ & $\mathrm{a}_{12}$ & $\mathrm{a}_{13}$ & $\leq$ & $\mathrm{b}_{1}$ \\
2 & $\mathrm{a}_{21}$ & $\mathrm{a}_{22}$ & $\mathrm{a}_{23}$ & $\leq$ & $\mathrm{b}_{2}$ \\
\hline
\end{tabular}

Model LP tersebut merupakan bentuk dan susunan yang mempunyai masalah-masalah yang akan dipecahkan dengan teknik LP.

Keterangan :

Zmaks = Nilai yang dioptimalkan yaitu nilai maksimasi, total penerimaan agroindustri buah stroberi setelah adanya optimasi. Dengan satuan rupiah $(\mathrm{Rp})$.

$1=$ Kendala bahan baku $(\mathrm{Kg})$

$2=$ Kendala tenaga kerja $(\mathrm{JKO})$

$\mathrm{X} 1=$ Jumlah hasil produksi dodol stroberi $(\mathrm{Kg})$

$\mathrm{X} 2=$ Jumlah hasil produksi selai stroberi $(\mathrm{Kg})$

$\mathrm{X} 3=$ Jumlah hasil produksi sirup stroberi $(\mathrm{Kg})$

$\mathrm{C} 1=$ Penerimaan dodol stroberi $(\mathrm{Rp})$
$\mathrm{C} 2=$ Penerimaan selai stroberi $(\mathrm{Rp})$

C3 = Penerimaan sirup stroberi $(\mathrm{Rp})$

a11 = Kebutuhan bahan baku untuk pembuatan dodol stroberi $(\mathrm{Kg})$

a12 = Kebutuhan bahan baku untuk pembuatan selai stroberi $(\mathrm{Kg})$

a13 = Kebutuhan bahan baku untuk pembuatan sirup stroberi $(\mathrm{Kg})$

b1 = Ketersediaan bahan baku stroberi $(\mathrm{Kg})$

a21 = Kebutuhan tenaga kerja untuk pembuatan dodol stroberi (JKO)

a22 = Kebutuhan tenaga kerja untuk pembuatan selai stroberi (JKO)

a23 = Kebutuhan tenaga kerja untuk pembuatan sirup stroberi (JKO)

b2 = Ketersediaan tenaga kerja (JKO)

\section{Kerangka Pemikiran}

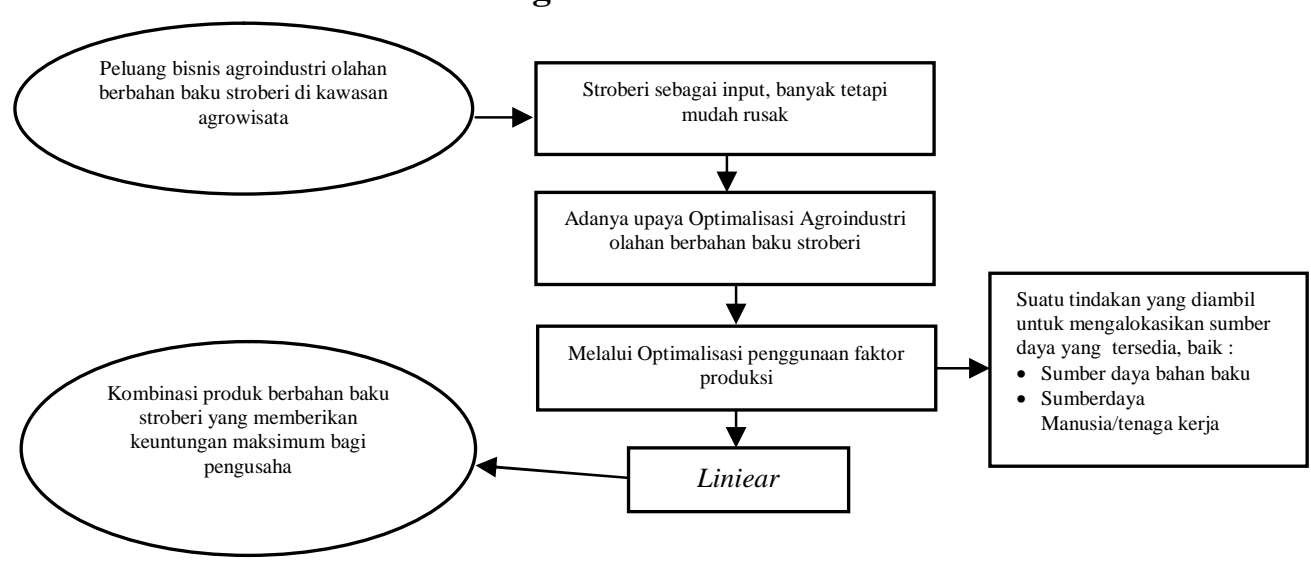

Gambar 1. Kerangka Pemikiran Optimasi Agroindustri Stroberi 


\section{Optimasi Agroindustri Stroberi \\ Optimization Agroindustri Strawberries \\ BETTY ROFATIN, HENDAR NURYAMAN DAN SUYUDI}

\section{HASIL DAN PEMBAHASAN \\ Kondisi Aktual Agroindustri Stroberi Penggunaan Bahan Baku}

Data yang digunakan berdasarkan produksi terakhir yang dilakukan agroindustri Kharisma pada saat penelitian, tercatat bahwa jumlah bahan baku yang dikorbankan oleh perusahaan untuk memproduksi dodol, selai dan sirup stroberi adalah $80 \mathrm{~kg}$. Dari $80 \mathrm{~kg}$ bahan baku yang tersedia, perusahaan mengalokasikan $40 \mathrm{~kg}$ per proses produksi untuk menghasilkan dodol stroberi sebanyak 30 $\mathrm{kg}$, sehingga untuk menghasilkan 1 kilogram dodol stroberi dibutuhkan 1,33 kilogram buah stroberi, pengolahan selai stroberi memerlukan $20 \mathrm{~kg}$ per proses produksi untuk menghasilkan selai sebanyak $12 \mathrm{~kg}$, oleh karena itu setiap 1 kilogram selai stroberi dibutuhkan 1,67 kilogram buah stroberi. Sedangkan dalam proses pengolahan sirup stroberi, memerlukan $20 \mathrm{~kg}$ untuk menghasilkan sirup stroberi sebanyak $17,5 \mathrm{~kg}$ (35 botol) per proses produksi, dengan demikian setiap 1 kilogram sirup stroberi dibutuhkan 1,14 kilogram buah stroberi. Lebih jelasnya dapat dilihat pada Tabel 2 .

Tabel 2. Penggunaan Bahan Baku (BB) Aktual

\begin{tabular}{lccc}
\hline \multicolumn{1}{c}{ Nama Produk } & Jumlah BB $(\mathrm{Kg})$ & Hasil Produksi $(\mathrm{Kg})$ & $\begin{array}{c}\text { Kebutuhan BB per 1 Kg Output } \\
(\mathrm{Kg})\end{array}$ \\
\hline Dodol & 40 & 30 & 1,33 \\
Selai & 20 & 12 & 1,67 \\
Sirup & 20 & 17,5 & 1,14 \\
\hline \multicolumn{1}{c}{ Jumlah } & 80 & 59,5 & - \\
\hline
\end{tabular}

Sumber : Data Primer Diolah (2015)

\section{Penggunaan Tenaga Kerja}

Penggunaan tenaga kerja aktual sebelum dilakukan optimasi untuk memproduksi dodol, selai dan sirup stroberi sebanyak 32 JKO. Proses produksi berlangsung selama 4 hari orang kerja (HOK) yang dilakukan Agroindustri Kharisma. Untuk memproduksi dodol sebanyak 30 kilogram dibutuhkan tenaga kerja 24 JKO, sehingga diketahui setiap 1 kilogram hasil produksi dodol dibutuhkan 0,80 JKO. Untuk memproduksi 12 kilogram selai stroberi dibutuhkan tenaga kerja $4 \mathrm{JKO}$, oleh karena itu diketahui setiap 1 kilogram hasil produksi selai dibutuhkan 0,33 JKO, dan Untuk memproduksi 17,5 kilogram (35 botol) sirup stroberi dibutuhkan tenaga kerja 4 JKO, maka untuk menghasilkan 1 kilogram hasil produksi sirup dibutuhkan 0,23 JKO. Lebih jelasnya dapat dilihat pada Tabel 3 .

Tabel 3. Penggunaan Tenaga Kerja (TK) Aktual

\begin{tabular}{lccc}
\hline Nama Produk & $\begin{array}{c}\text { Jumlah TK } \\
(\mathrm{JKO})\end{array}$ & $\begin{array}{c}\text { Hasil Produksi } \\
(\mathrm{Kg})\end{array}$ & $\begin{array}{c}\text { Kebutuhan TK per 1 Kg } \\
\text { Output (JKO) }\end{array}$ \\
\hline Dodol & 24 & 30 & 0,80 \\
Selai & 4 & 12 & 0,33 \\
Sirup & 4 & 17,5 & 0,23 \\
\hline \multicolumn{1}{c}{ Jumlah } & 32 & 59,5 & - \\
\hline
\end{tabular}

Sumber : Data Primer Diolah (2015)

\section{Penerimaan Agroindustri Stroberi}

Berdasarkan analisis aktual mengenai penggunaan bahan baku dan tenaga kerja, menunjukkan total produksi yang dihasilkan sebesar 59,5 kilogram dengan total penerimaan Rp. 2.505.000,- untuk satu kali produksi (4 hari). Produk total terdiri dari 30 kilogram dodol stroberi dengan harga jual Rp. 50.000,- per kilogram, maka diperoleh penerimaan sebesar Rp. 1.500.000,--. hasil produksi 12 kilogram selai stroberi dengan harga jual Rp. 40.000,- per kilogram, maka diperoleh penerimaan sebesar Rp. 480.000,-. hasil produksi 17,5 kilogram ( $\approx 35$ botol) sirup stroberi dengan harga jual Rp. 30.000,- per kilogram (Rp. 15.000 per botol), maka 


\section{AIMBAR AGRIBISNIS \\ ISSN 2460-4321 \\ Volume 1 • Nomor 3 - Juli 2016}

diperoleh penerimaan sebesar Rp. 525.000,-. $\quad$ Lebih jelasnya dapat dilihat pada Tabel 4.

Tabel 4. Penerimaan Aktual

\begin{tabular}{lrcc}
\hline \multicolumn{1}{c}{ Output } & $\begin{array}{c}\text { Hasil Produksi } \\
(\mathrm{Kg})\end{array}$ & Harga $(\mathrm{Rp} / \mathrm{Kg})$ & Penerimaan (Rp) \\
\hline Dodol & 30 & 50.000 & 1.500 .000 \\
Selai & 12 & 40.000 & 480.000 \\
Sirup & 17,5 & 30.000 & 525.000 \\
\hline \multicolumn{1}{c}{ Jumlah } & 59,5 & - & 2.505 .000 \\
\hline
\end{tabular}

Sumber : Data Primer Diolah (2015)

\section{Kondisi Optimal Agroindustri Stroberi Penggunaan Bahan Baku}

Penggunaan bahan baku optimal hasil analisis Linear Programming untuk produksi dodol, selai dan sirup stroberi adalah dengan mengalikan masing-masing hasil produksi yang telah diketahui dari perhitungan dengan menggunakan bahan baku per 1 kilogram dari masing-masing output. Hasil analisis menunjukkan perusahaan dianjurkan untuk memproduksi dodol stroberi sebanyak 29,83 kilogram, sirup stroberi sebanyak 35,37 kilogram $(70,74$ botol $\approx 71$ botol) dan tidak memproduksi selai stroberi. Untuk memproduksi 29,83 kilogram dodol stroberi, perusahaan harus mengalokasikan bahan baku sejumlah 39,67 kilogram, diperoleh dari hasil kali hasil produksi dengan penggunaan bahan baku per 1 kilogram output. Begitu juga untuk
35,37 kilogram ( $\approx 71$ botol) sirup stroberi, perusahaan harus mengalokasikan 40,33 kilogram bahan baku diperoleh dari hasil produksi dikali 1,14 kilogram penggunaan bahan baku per 1 kilogram outputnya. Sedangkan untuk produksi selai stroberi tidak ada aktifitas, karena semua ketersediaan bahan baku telah habis terserap oleh produksi dodol dan sirup stroberi. Selai stroberi dinilai kurang memberikan penerimaan yang besar, karena dianggap tidak sebanding dengan penyerapan bahan baku yaitu 20 kilogram dan menghasilkan output hanya 4 kilogram, jika dibandingkan dengan sirup yang membutuhkan bahan baku yang sama 20 kilogram tetapi menghasilkan output lebih banyak yaitu 17,5 kilogram dilihat pada kondisi aktualnya. Lebih jelasnya dapat dilihat pada Tabel 5 .

Tabel 5. Penggunaan Bahan Baku Optimal

\begin{tabular}{lccc}
\hline \multicolumn{1}{c}{ Nama Produk } & $\begin{array}{c}\text { Hasil Produksi } \\
(\mathrm{Kg})\end{array}$ & $\begin{array}{c}\text { Penggunaan BB per } \\
1 \text { Kg Output }(\mathrm{Kg})\end{array}$ & \multirow{2}{*}{ Jumlah BB $(\mathrm{Kg})$} \\
\hline Dodol & 29,83 & 1,33 & 39,67 \\
Selai & 0,00 & 0,00 & 0,00 \\
Sirup & 35,37 & 1,14 & 40,33 \\
\hline \multicolumn{1}{c}{ Jumlah } & 65,20 & - & 80,00 \\
\hline
\end{tabular}

Sumber : Data Primer Diolah (2015)

\section{Penggunaan Tenaga Kerja}

Penggunaan tenaga kerja optimal hasil analisis Linear Programming untuk produksi dodol, selai dan sirup stroberi menunjukkan penggunaan tenaga kerja per 1 kilogram output dibutuhkan 0,8 JKO sehingga tenaga kerja yang dibutuhkan untuk menghasilkan 29,83 kilogram output adalah sebanyak 23,86 JKO, sementara itu diketahui untuk menghasilkan 1 kilogram sirup stroberi dibutuhkan 0,23 JKO sehingga untuk memproduksi output 35,37 kilogram $(\approx$ 71 botol) membutuhkan tenaga kerja 8,14 JKO. 


\section{Optimasi Agroindustri Stroberi \\ Optimization Agroindustri Strawberries \\ BETTY ROFATIN, HENDAR NURYAMAN DAN SUYUDI}

Sementara untuk selai stroberi tidak aktifitas, karena ketersediaan tenaga kerja habis untuk memproduksi dodol dan sirup stroberi, dengan total tenaga kerja yang dibutuhkan adalah sebesar 32 JKO. Lebih jelasnya dapat dilihat pada Tabel 6.

Tabel 6. Penggunaan Tenaga Kerja (TK) Optimal

\begin{tabular}{lccc}
\hline \multicolumn{1}{c}{ Nama Produk } & $\begin{array}{c}\text { Hasil Produksi } \\
(\mathrm{Kg})\end{array}$ & $\begin{array}{c}\text { Penggunaan TK per 1 } \\
\text { Kg Output (JKO) }\end{array}$ & $\begin{array}{c}\text { Penggunaan TK } \\
(\mathrm{JKO})\end{array}$ \\
\hline Dodol & 29,83 & 0,80 & 23,86 \\
Selai & 0,00 & 0,00 & 0,00 \\
Sirup & 35,37 & 0,23 & 8,14 \\
\hline \multicolumn{1}{c}{ Jumlah } & 65,20 & - & 32,00 \\
\hline
\end{tabular}

Sumber : Data Primer Diolah (2015)

\section{Penerimaan Agroindustri Stroberi}

Penerimaan optimal diperoleh dengan menggunakan formulasi untuk mencari total penerimaan adalah sebagai berikut :

$$
\begin{aligned}
\mathrm{Z}= & \mathrm{P} 1 \mathrm{X} 1+\mathrm{P} 2 \mathrm{X} 2+\mathrm{P} 3 \mathrm{X} 3 \\
= & 50.000(29,83)+40.000(0) \\
& +30.000(35,37) \\
= & 2.552 .716,-
\end{aligned}
$$

Hasil optimasi akan memberikan penerimaan kepada perusahaan sebesar Rp.
2.552.716,- dari total produksi olahan buah stroberi yaitu 65,20 kilogram, dengan rincian untuk output dodol stroberi sebesar 29,83 kilogram dan sirup stroberi 35,37 kilogram (70,74 botol $\approx 71$ botol), dimana harga jual dodol stroberi per kilogramnya adalah Rp. 50.000,- maka penerimaan untuk dodol stroberi sebesar Rp. 1.491.505,- dan harga jual untuk sirup stroberi per kilogramnya sebesar Rp. 30.000,- (per botolnya Rp. 15.000,-), maka penerimaan dari sirup stroberi sebesar Rp. 1.061.211,--

Tabel 10. Penerimaan Agroindustri Stroberi Optimal

\begin{tabular}{lccc}
\hline \multicolumn{1}{c}{ Nama produk } & $\begin{array}{c}\text { Jumlah Output } \\
(\mathrm{Kg})\end{array}$ & Harga $(\mathrm{Rp} / \mathrm{Kg})$ & Penerimaan (Rp) \\
\hline Dodol & 29,83 & 50.000 & 1.491 .505 \\
Selai & 0,00 & 40.000 & 0 \\
Sirup & 35,37 & 30.000 & 1.061 .211 \\
\hline \multicolumn{1}{c}{ Jumlah } & 65,20 & - & 2.552 .716 \\
\hline
\end{tabular}

Sumber : Data Primer Diolah (2015)

\section{Selisih Penerimaan Sebelum dan Setelah Dilakukan Optimasi}

Terdapat perbedaan antara besar penerimaan yang menggunakan solusi optimal dengan keadaan aktualnya, secara aktual jumlah produksi agroindustri stroberi menjadi dodol, selai serta sirup adalah sebesar 59,5 kilogram dengan rincian 30 kilogram dodol stroberi, 12 kilogram selai stroberi dan 17,5 kilogram sirup stroberi. Berbeda dengan hasil optimasi yang menunjukkan jumlah dari ketiga output tersebut adalah 65,20 kilogram dengan rincian 29,83 kilogram dodol stroberi dan sirup stroberi 35,37 kilogram. Jika dilihat dari jumlahnya, output secara aktual lebih kecil dibanding secara optimal. Perbedaan dari kedua analisis tersebut adalah tidak adanya aktifitas produksi selai stroberi sebanyak 12 kilogram, jika dilihat dari besarnya penerimaan ada perbedaan walaupun perbedaannya tidak begitu besar. Dilihat dari penggunaannya, ketersediaan bahan baku dan tenaga kerja habis digunakan untuk kegiatan produksi yaitu bahan baku sebanyak 80 kilogram dan tenaga kerja sebanyak 32 jam kerja orang (JKO).

Secara optimal perusahaan mampu menghasilkan penerimaan sebesar Rp. 2.552.716,- berbeda dengan secara aktual dimana jumlah nominal yang diterima perusahaan adalah Rp. 2.505.000,- dari ketiga 


\section{AIMBAR AGRIBISNIS \\ ISSN 2460-4321 \\ Volume 1 • Nomor 3 - Juli 2016}

produk berbahan baku stroberi. Sehingga selisih antara aktual dengan solusi optimal sebesar Rp. 47.716,- per satu kali produksi. Dilihat dari perbedaan penerimaan tersebut yang tidak begitu besar, maka tidak menutup kemungkinan selai stroberi masih tetap dapat diproduksi untuk memenuhi permintaan konsumen.

\section{KESIMPULAN DAN SARAN \\ Kesimpulan}

1. Kondisi aktual agroindustri berbahan baku stroberi pada usaha Agroindustri Kharisma berdasarkan penggunaan bahan baku adalah 40 kilogram untuk dodol stroberi, 20 kilogram untuk selai stroberi dan 20 kilogram untuk sirup stroberi. Berdasarkan penggunaan tenaga kerja adalah 24 JKO untuk dodol stroberi, 4 JKO untuk selai stroberi dan 4 JKO untuk sirup stroberi, sehingga dengan 30 kilogram dodol stroberi, 12 kilogram selai dan 17,5 kilogram ( $\approx 35$ botol) sirup stroberi, diperoleh total penerimaan sebesar Rp. 2.505.000,-

2. Kondisi optimal agroindustri berbahan baku stroberi pada usaha Agroindustri Kharisma, berdasarkan penggunaan bahan baku adalah 39,67 kilogram untuk dodol stroberi, 40,33 kilogram untuk sirup stroberi dan tidak memproduksi selai stroberi. Berdasarkan penggunaan tenaga kerja adalah 23,86 JKO untuk dodol stroberi, 8,14 JKO untuk sirup stroberi, sehingga dengan 29,83 kilogram dodol stroberi dan 35,37 kilogram ( $\approx 1$ botol) sirup stroberi diperoleh total penerimaan Rp. 2.552.716,--

3. Selisih penerimaan sebelum dan setelah dilakukan optimasi adalah Rp. 47.716,-.

\section{Saran}

1. Jika perusahaan dihadapkan pada kasus yang sama, disarankan untuk menggunakan solusi optimal, karena solusi optimal lebih baik dibandingkan kondisi aktual yang mana jumlah penerimaan yang akan diterima oleh perusahaan lebih besar dibandingkan dengan aktual.

2. Secara optimal harus mengorbankan atau tidak memproduksi selai stroberi, karena ketersediaan bahan baku dan tenaga kerja akan habis oleh produksi dodol dan sirup stroberi. Tetapi jika kondisi perusahaan memaksakan untuk melakukan lebih banyak diversifikasi produk berbahan baku stroberi, solusi yang dapat ditawarkan adalah dengan menggunakan tambahan input yang nantinya dapat digunakan untuk memproduksi produk lainnya diantaranya selai stroberi.

3. Perlu dilakukan penelitian lanjutan, agar hasil penelitian ini dapat lebih berguna khususnya bagi pengusaha agroindustri stroberi dalam menjalankan usahanya.

\section{DAFTAR PUSTAKA}

Deswani P, Masrul D, Santosa. 2014. Optimasi Perencanaan Keuntungan Produksi Pada Pengolahan Rendang Di Perusahaan "Rendang Erika" Payakumbuh. Jurnal Optimasi Sistem Industri, Vol. 13 No. 1 : 427-453.

J. Supranto. 1983. Linear programming. Fakultas Ekonomi Universitas Indonesia. Jakarta

J. Suprantto. 1983. Teknik Pengambilan Keputusan. Rineka Cipta. Jakarta.

Melli S, Elwamendri, Ira W, Nena M. 2012. Optimasi Penggunaan Faktor Produksi Usahatani Kedelai Dan Padi Ladang Di Kecamatan Tebo Ilir Kabupaten Tebo. Prosiding Seminar Nasional dan Rapat Tahunan Bidang Ilmu-Ilmu Pertanian BKS-PTN Wilayah Barat; Medan 3-5 April 2012. Hlm 499-507.

Mitchan, E.J, C.H. Crisosto dan A.A. Kader. 2000. Recommendation for maintaning Posharvest Quality. Departement of Vegetable Crops. University of california. Davis.

Moehar Daniel. 2002. Pengantar Ekonomi Pertanian. PT Bumi Aksara. Jakarta.

Muslimin Nasution. 2002. Pengembangan Kelembagaan Koperasi Pedesaan untuk Agroindustri. IPB Press. Bogor.

Nasikh. 2009. Model Optimalisasi Faktor Produksi Usaha Industri Kecil Mebel Kayu Jati di Pasuruan Jawa Timur. Jurnal Manajemen Dan Kewirausahaan, Vol.11, No. 1: 85-93. 


\section{Optimasi Agroindustri Stroberi \\ Optimization Agroindustri Strawberries \\ BETTY ROFATIN, HENDAR NURYAMAN DAN SUYUDI}

Pangestu Subagyo, Marwan Asri, Titani Handoko. 2000. Dasar-dasar Operations Research Edisi 2. Yogyakarta : BPFE.

Rahmat Rukmana. 1998. Stroberi Budidaya dan Pascapanen. Penerbit Kanisius. Yogyakarta.

Soekartawi. 1992. Linear Programming. CV Rajawali. Jakarta Utara.

Sri Mulyono. 2007. Riset Operasi. Fakultas Ekonomi Universitas Indonesia. Jakarta.

Supriatin Budiman dan Desi Saraswati. 2008. Berkebun Stroberi Secara Komersial. Penebar Swadaya. Jakarta.

Tarmizi. 2005. Pengertian Optimasi dan Linear. http://kuliah itu keren. blogspot. com. [10 Juli 2015].

Qanytah, Sri Catur Budi S dan Indrie Ambarsari. 2011. Teknologi Pengolahan Dodol dan Selai Strawberry. Rekomendasi Paket Teknologi Pertanian Jawa Tengah. 


\section{AIMBAR \\ AgRIBISNIS \\ ISSN 2460-4321 \\ Volume 1• Nomor 3• Juli 2016}

Halaman | 290 